\title{
Design and setup of a low calorific SOFC off-gas combustion chamber for a pressurized MGT hybrid power plant test rig
}

\author{
Timo Lingstädt ${ }^{1,{ }^{*}}$, Felix Grimm $^{1}$, Peter Kutne $^{1}$, and Manfred Aigner ${ }^{1}$ \\ ${ }^{1}$ German Aerospace Center (DLR), Institute of Combustion Technology, 70569 Stuttgart, Germany
}

\begin{abstract}
A demonstrator system for a hybrid power plant is currently being built at DLR, designed for an electrical power output level of $30 \mathrm{~kW}$. Since the very low energy dense exhaust gas of the fuel cell anode side represents the fuel for the combustion chamber in this application, a low calorific SOFC off-gas combustor was developed at DLR specifically for this use case. With thorough investigations on the atmospheric test rig, the expected operational range of the combustor was quantified in preceding works. Now, a novel machine design, including dilution air with an adjustable air split configuration is derived to validate the gathered information on the micro gas turbine test rig under pressurized machine conditions. This work explains the design of the combustion system and addresses the different design features specifically implemented for this use case. Since simplifications had to be made for the atmospheric combustor prototype, a significant positive influence on the operational envelope is expected with the transition to the machine configuration.
\end{abstract}

\section{Nomenclature}

$\begin{array}{lll}\text { CFD } & - & \text { Computational fluid dynamics } \\ \text { DLR } & - & \text { Deutsches Zentrum für Luft- und Raumfahrt / German Aerospace Center } \\ \text { FLOX } & - & \text { Flameless oxidation } \\ \text { MGT } & - & \text { Micro gas turbine } \\ \text { SOFC } & - & \text { Solid oxide fuel cell } \\ \text { TOT } & - & \text { Turbine outlet temperature }\end{array}$

\section{Introduction}

With the focus on future decentralized energy production, the hybrid power plant, combining a micro gas turbine with a solid oxide fuel cell, is a promising concept. It fulfils high electrical efficiency and a relatively wide operational range as well as fuel and operational flexibility [1]. A demonstrator system for such a hybrid power plant is currently being built at DLR Stuttgart. Since the exhaust gases from the fuel cell have considerably

* Corresponding author: timo.lingstaedt@dlr.de 
low energy content and contain a high amount of reaction products, a combustor was developed at DLR for this specific use case. It was investigated experimentally and numerically under atmospheric conditions on an atmospheric test rig for the expected operating conditions [2, 3]. However, the influence of pressure and dilution air is not considered and especially additional heat losses due to the optical accessibility of the atmospheric test rig do not represent the real boundary conditions in the machine configuration. Based on the investigated combustor, a combustion system for the micro gas turbine test rig, including dilution air distribution, is derived and manufactured. In the micro gas turbine test rig at DLR, the influence of the previously not considered factors will be investigated in the near future.

\section{Combustion chamber design}

The machine configuration of the SOFC off-gas combustion chamber is designed in a modular fashion with a pressure-retaining housing and three main internal components as shown in Fig. 1. The outlet ring (pink), liner (orange) and integral combustor and fuel plenum (yellow) are stacked axially within the pressure housing (gray). The ignitor (red) is mounted radially in front of a nozzle permeating the pressure housing and the liner. The fuel is fed to the plenum area from one side as described in Sec. 2.1 while the process air is introduced from the left side in Fig. 1.

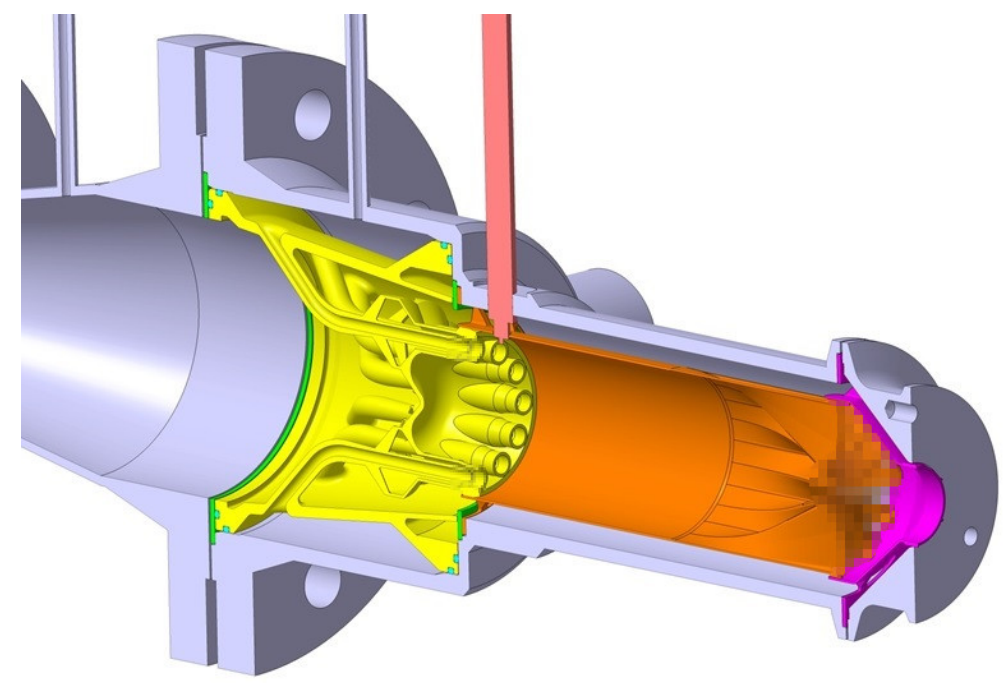

Fig. 1. Combustion chamber overview with integral combustor and fuel plenum (yellow), liner (orange), outlet (pink) and ignitor (red).

The fuel feed and plenum as well as the air supply side is equipped with sockets for temperature and pressure measurement. Additionally, the critical housing metal temperature can be monitored via surface temperature sensors.

To reduce thermal losses, the overall structure is enclosed by high temperature insulation material. 


\subsection{Fuel and air supply}

The emulated off-gas of the fuel cell is generated by a hot steam generator, which has already been used in the carried out investigations in the atmospheric test rig, as described in more detail in [2], [3] and [4]. Essentially, the desired gas composition, namely a mixture of $\mathrm{H}_{2}, \mathrm{CO}$ and optionally natural gas as combustible species, as well as $\mathrm{H}_{2} \mathrm{O}$ and $\mathrm{CO}_{2}$ as non-reacting components, is provided by the device under high temperature conditions. This generated off-gas is then fed into a fuel plenum, which encloses the combustor circumferentially as shown in Fig. 2. From here, the individual fuel nozzles are supplied with the gas mixture through pipes integrated in the combustor module manufactured in selective laser melting technology.

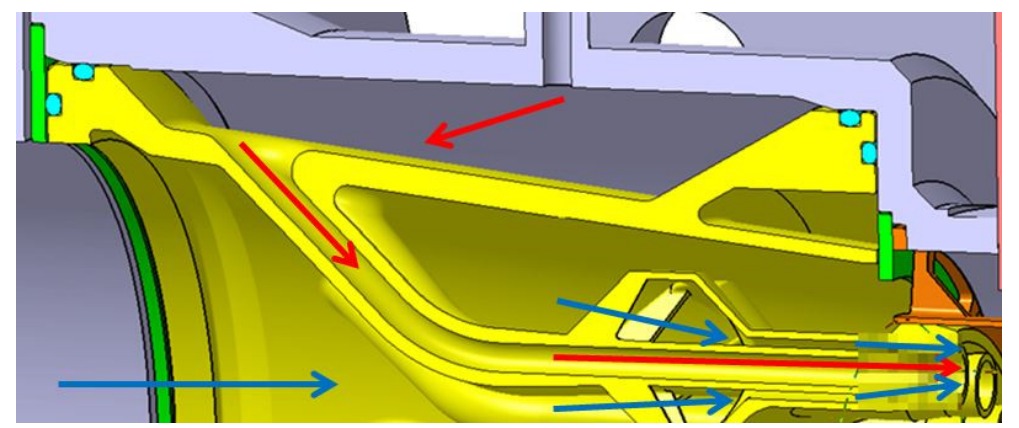

Fig. 2. Fuel (emulated SOFC anode off-gas, forming gas, natural gas or biogas) distribution (red arrows) via circumferential plenum and individual nozzle supply and air (emulated SOFC cathode off-gas with reduced oxygen content) distribution to the coaxially aligned air nozzles (blue arrows).

The air is supplied axially, split and partially directed into the twelve air nozzles via funnel-shaped inlets. This FLOX®-similar concept was initially designed for use in industrial furnaces $[5,6]$. The separate fuel nozzles are coaxially aligned as illustrated in Fig. 2. A significant portion of the process air is passing outside of the liner and is fed back into the process as dilution air behind the combustor as described in Sec. 2.3.

\subsection{Air split configuration}

In order to be able to adjust the air split, representing the amount of air fed directly to the combustor divided by the overall air flow including dilution air, a set of interchangeable orifices was manufactured. The choice of the used orifice allows for an adjustment of the air split in the range of $18.4 \%$ to $22.4 \%$ according to steady state CFD simulations. With the results from previous investigations on the atmospheric test rig, it is possible to tune the combustion chamber towards a desired behavior regarding emissions and operational range [3]. The position and working principle is illustrated in Fig. 3 with the green part representing the removable orifice.

With the use of a smaller open flow cross section in the dilution air path, more air is forced through the nozzles into the core combustor. Since this additional throttling is connected with a shift in pressure loss, this method is only feasible in a restricted range to not exceed the differential pressure limitations [4] dictated by the fuel cell specification. 


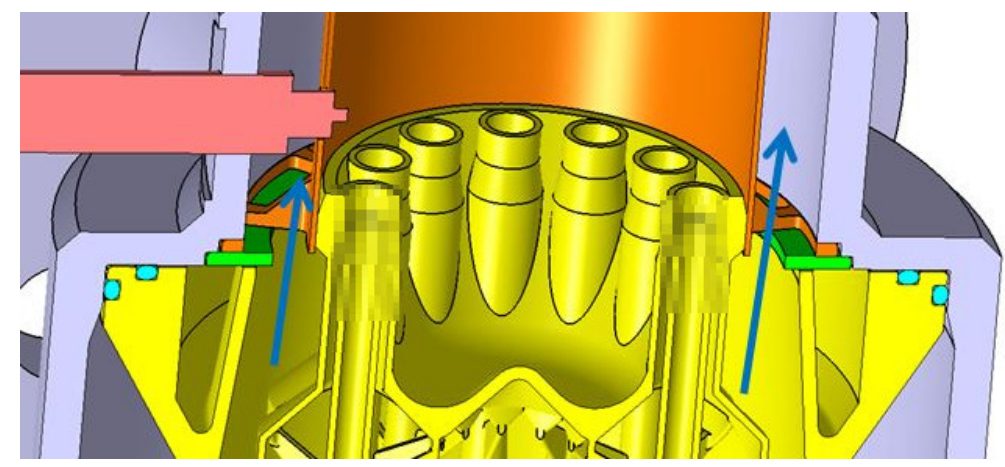

Fig. 3. Variable air split configuration in the range of $18.4 \%$ to $22.4 \%$ (according to steady state CFD simulations) realized via an inserted individually sized restricting orifice (green) in the dilution air path.

\subsection{Dilution air concept}

A unique design feature of the presented combustion chamber is the method of mixing in the dilution air as previously mentioned in Sec. 2.1. Several attempts of standard dilution air hole configurations were investigated using steady state CFD simulations. It was found that, for the specific boundary conditions and limitations especially regarding allowed pressure differences by the fuel cell between fuel and air supply side of the combustor, it was not possible to realize a standard dilution hole design. Because of the limitation in pressure difference the classic concept did not allow for a sufficient dilution air flow unless the entire liner was covered with holes. Additionally, because of a lack of differential pressure, the dilution air did not penetrate the core flow sufficiently to realize a moderate and even temperature distribution over the outlet cross section.

With the introduced mixing nozzle design, as illustrated in Fig. 4, these difficulties are addressed. The liner outlet shape forces the cool dilution air closer to the core of the exhaust flow while redirecting the hot exhaust gases more towards the outer regions of the combustion chamber.

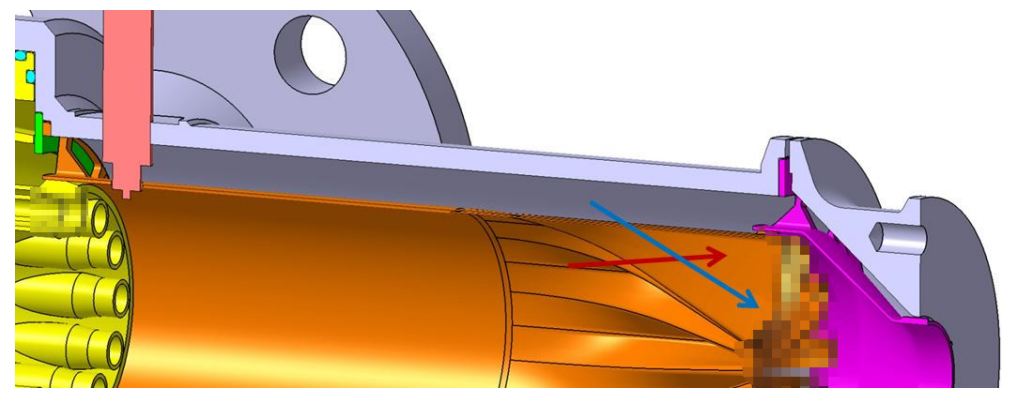

Fig. 4. Liner design with mixing nozzle enhancing radial combustion chamber outlet temperature profile compared to standard dilution holes. The relatively cool dilution air (approx. 1050 K) is redirected into the center section of the hot inner exhaust flow while the hot gas from the core is forced towards the outside areas. 
Because of the unique shape, this is possible without a high amount of differential pressure necessary, as needed with classic jet in crossflow dilution hole designs. The design generates slightly higher thermal stresses on the metal of the liner where the hot core flow hits the part. The expected metal temperatures were reduced sufficiently by the addition of cooling fins to the slats of the liner outlet, improving the convective heat transfer to the dilution air flow.

A comparison of the expected radial temperature distribution between the mixing nozzle design and the classic dilution hole approach is shown in Fig. 5.

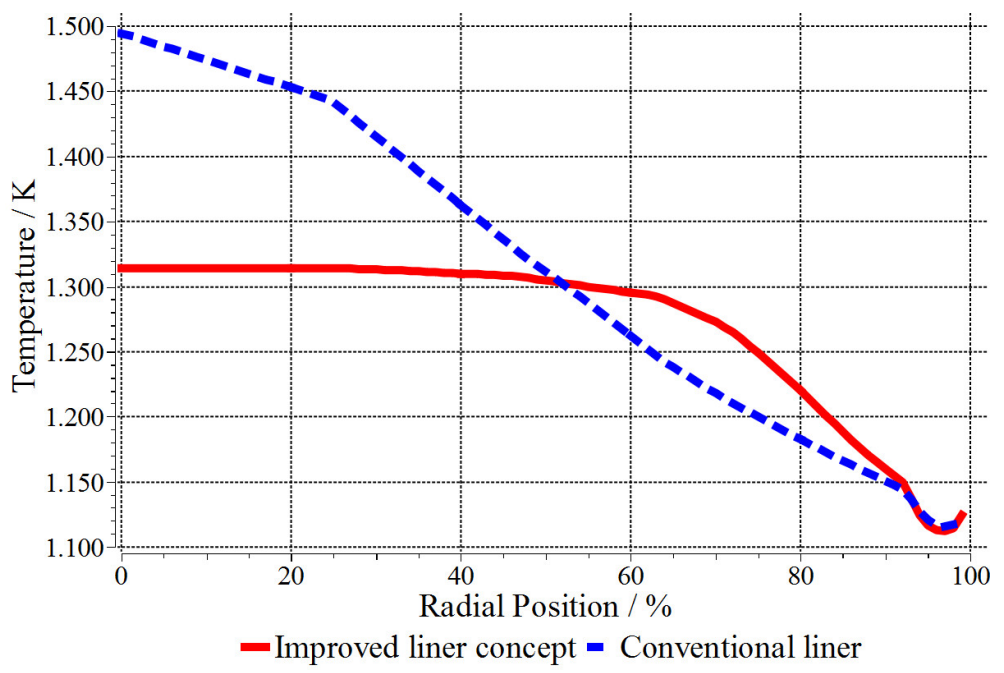

Fig. 5. Improvement of temperature distribution over radial turbine inlet cross sectional profile (solid red line) compared to initial standard dilution hole design (dashed blue line). Possible reduction of peak temperatures in turbine inlet profile is expected to be in the range of $180 \mathrm{~K}$ (according to steady state CFD simulations).

The benefits are clearly visible in terms of peak temperature reduction from approx. $1500 \mathrm{~K}$ down to $1320 \mathrm{~K}$. The occurring peak temperature limits the realizable target turbine outlet temperature due to material stress. Additionally, a more uniform temperature distribution in radial direction is achieved.

\subsection{Thermal expansion}

Thermal expansion of the different components was an important topic to address, since it can influence the flow paths, when occurring in critical positions and blocking the air flow or even damaging the material.

For this combustion chamber, especially the axial expansion was addressed by working from the ignitor position as a fixed point. The axial position of the liner is defined by the location of the ignitor. The liner is able to expand under heat effect into the outlet ring. The connection is designed as a loose sliding fit, allowing also for expansion in radial direction, as marked in Fig. 6. 


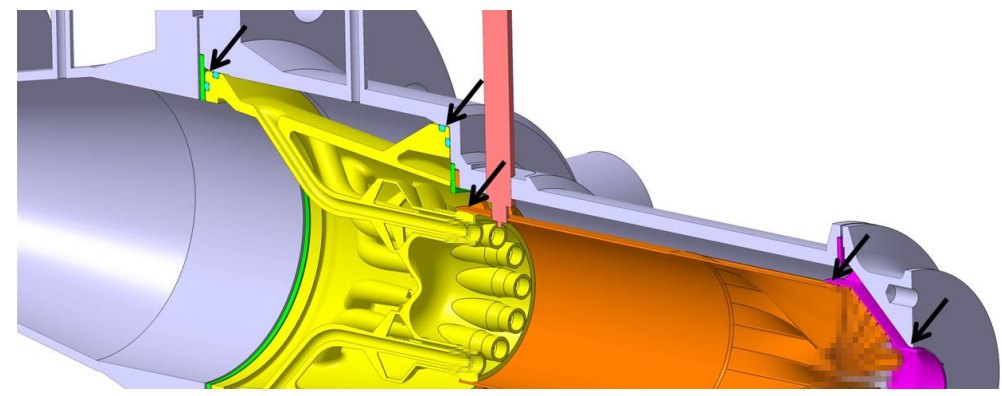

Fig. 6. Sliding fits at critical positions (marked with arrows) to allow for thermal expansion in axial direction of the core components. Fixed point is the ignitor position defining the axial alignment of the liner. All other components can adjust accordingly.

Axial and radial expansion of the integral combustor and fuel plenum unit is allowed by the sealing strategy with high temperature sealing ropes. The initial gap and dynamic movement capability of the sealing material is designed to handle the expected temperature differences between the unit and the housing reversibly.

The interface between the combustor and the liner is designed as a sliding fit as well. The inevitable leakage flow through the resulting gap is expected to be negligible and to not influence the combustion in a negative way.

The outlet ring is axially supported between the flanges and free in axial movement towards the downstream end. Hence, it can expand into the turbine housing if necessary.

\section{Commissioning in the test rig}

A successful first run-up with the new combustion system using natural gas is achieved. The performed short cycle from start, ignition, run-up to part load conditions and shutdown procedure is shown in Fig. 7.

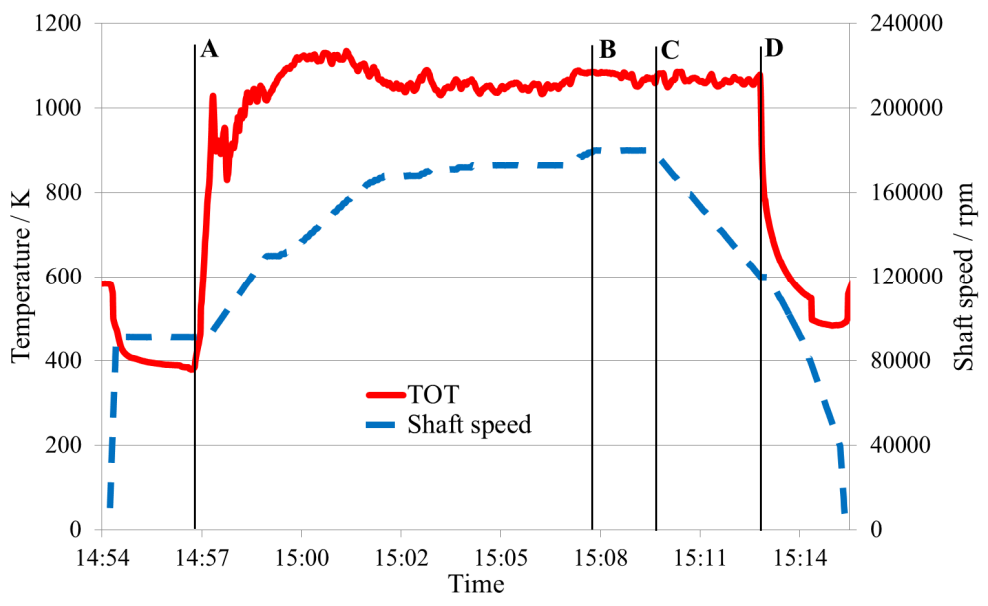

Fig. 7. Start-up, ignition (A) and ramp-up procedure with off-gas combustion chamber operation using natural gas. Switch to closed loop TOT controller at part load conditions (B) with following ramp-down (C) and shut-down (D) maneuvers. 
As illustrated, a successful ramp-up procedure with turbine outlet temperatures (TOT) within limitations is realized. Activating the closed loop TOT controller entering partload conditions is possible and its control behavior during partload operation and ramp-down is satisfactory. The integration of the combustion system in the hybrid power plant test rig is completed and it will be tested first with natural gas and then operated with biogas as well as emulated SOFC off-gas in the near future.

\section{Conclusions and Outlook}

A combustion system for low calorific SOFC off-gas was designed, manufactured and integrated into the pressurized hybrid power plant test rig based on previous investigations on the atmospheric test rig. The different specific design features were presented. The system was commissioned successfully with a short first run using natural gas and it will be tested further with natural gas and then operated with biogas as well as emulated SOFC offgas.

The performance of the combustor was investigated in previous works and an expected operational envelope was found $[1,2]$. Since the heat losses are expected to be significantly lower in the insulated combustion chamber than in the atmospheric test cases, the performance in terms of operational range for low power operation and $\mathrm{CO}$ emissions level is expected to improve substantially.

The complete operational range of the hybrid power plant from start-up, different load levels and shut-down procedures will be emulated and investigated regarding the combustion system operation including emulated SOFC operation with corresponding offgas compositions and flow and temperature boundary conditions. The results will be compared to the results of the atmospheric experiments and represent the basis for further numerical investigations, especially regarding the transition from low calorific atmospheric test cases towards pressurized machine conditions.

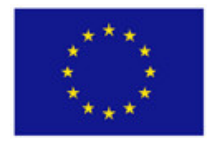

This project has received funding from the European Union's Horizon 2020 research and innovation programme under grant agreement No 641073 (www.bio-hypp.eu).

\section{References}

1. M. Hohloch, A. Huber, M. Aigner, Analysis of Operational Strategies of a SOFC/MGT Hybrid Power Plant, Proceedings of the ASME Turbo Expo, (2017), GT2017-65013

2. T. Lingstädt, F. Grimm, T. Krummrein, S. Bücheler, M. Aigner, Experimental investigations of an SOFC off-gas combustor for hybrid power plant usage with low heating values realized by natural gas addition, Proceedings of GPPS Forum, (2018), GPPS-2018-0052

3. T. Lingstädt, F. Grimm, T. Krummrein, P. Kutne, M. Aigner, Atmospheric Experimental Investigations of a Jet-Stabilized SOFC Off-Gas Combustor for a Hybrid Power Plant operated with Biogas, AIAA SciTech Forum, (2019)

4. S. Bücheler, A. Huber, M. Aigner, Development of a Jet-Stabilized Combustion System for the use of Low-Caloric SOFC Off-Gas, Proceedings of the ASME Turbo Expo, (2017), GT201764447

5. J. Wünning, Flameless oxidation to reduce thermal NO-formation, Progress in Energy and Combustion Science (1997), 23(1), 81-94, DOI:10.1016/S0360-1285(97)00006-3

6. A. Cavaliere, M. Joannon, Low NOx Combustion Technologies for High Temperature Applications, Progress in Energy and Combustion Science (2004), 30(4), 329-366, DOI:10.1016/j.pecs.2004.02.003 